\title{
2 BITS: A case of mass customization for social housing
}

\section{SIGRADI2018 TECHNOPOLITICAS \\ xxii congresso da sociedade iberoamericana de gráfica digital 22th conference of the iberoamerican society of digital graphics 07|08|09|novembro|2018 iau usp | são carlos | sp br}

\author{
Jorge Lira de Toledo e Gazel \\ Universidade Federal de Viçosa | Brazil | lirajorge4@gmail.com
}

Andressa Carmo Pena Martinez

Universidade Federal de Viçosa | Brazil | andressamartinez@gmail.com

Denise Mônaco dos Santos

Universidade Federal de Viçosa | Brazil | denisemonaco.s@gmail.com

Douglas Lopes de Souza

Universidade Federal de Viçosa | Brazil | dglopes@gmail.com

\begin{abstract}
This work presents a design for mass customization of modular housing applied to the Brazilian case, through modeling in grasshopper. These parametric tools contribute to an increase in the flexibility of the decisions and allow the execution, generating a wide range of solutions for the same problem. As a case study, it was considered the environmental disaster which occurred in the city of Mariana, whose homeless population remains displaced. Although in the initial phase of studies, this modular housing model aims to discuss principles of variability, flexibility, and pre-fabrication, delegating more decisions to end-users of large-scale social housing.
\end{abstract}

Keywords mass customization; parametric design; social housing

\section{INTRODUCTION: HOUSING POLICY IN BRAZIL}

The deficiency in the Brazilian housing sector is a historical problem and its solution has been the target of several public policies over the last decades. It is consensual in the literature (Santos, 2009; Boduki, 2008) that there are three main periods into Brazilian housing policy: before 1964 (pre-BNH); from 1964 to 1986 (BNH operation period); and post 1986 (post-BNH). In the period between the end of the BNH (1986) and the creation of the Ministry of Cities (2003), seven different administrative structures were created to regulate the country's housing policies. In the last decade, to create a far-reaching housing policy from a national perspective, the government facilitated access to real estate credit. In addition, "the creation of Minha Casa Minha Vida Program (PMCMV) in 2009, to serve low-income families, heated the housing industry in an unprecedented way" (Whitaker, 2012). After 9 years of the inauguration of the PMCMV and more than U\$ 150 billion invested, four million housing units were built, of which more than three million were delivered. When quantitatively analyzed, the PMCMV represents a milestone in the history of the country, however, the analysis from the qualitative point of view, generated severe criticism of the program:

"Across the country, new neighborhoods emerge in distant and undeveloped areas, lining up hundreds of identical and minuscule houses, or lining up residential towers with poor constructive standards, and great impact on the environment. In this context, the question that comes naturally is: what are the provoked results in the Brazilian urban scenario in the coming years?" (WHITAKER, 2012, p.7, translated by the authors).
The government's difficulties in dealing with the housing problem and the continued population growth generate an ever-increasing demand for housing units. In the case of the lower income population, the housing policy uses the cost reduction model, based on the mass production of standardized units, with a minimum size of $45.00 \mathrm{~m}^{2}$, with little flexibility in the internal subdivision of the rooms, a lack of volumetric variability and surface customization. The standardization of the units and the strategy of minimum dimensions do not consider the variability of the family profile, and the number of members; the standard implantation in the lot does not consider criteria of indoor environmental comfort, insolation, and ventilation; the process and methods of construction are slow and generate large volumes of waste. The need for more efficient design methods, from a qualitative, constructive and financial point of view, is becoming more urgent in the country.

In face of this reality, this work starts from the hypothesis of mass customization applied to the Brazilian housing scenario, using as a specific assumption the case of the environmental disaster that occurred in Mariana, Minas Gerais.

In November 2015, the Fundão dam, located in the subdistrict of Bento Rodrigues, in the city of Mariana, broke, releasing a flood of mud, leaving 19 people dead, thousands homeless, as well as causing serious environmental and socioeconomic damages along the Doce River Basin. Among the seven affected communities and sub-districts, Bento Rodrigues is the most affected, with 207 out of 252 buildings compromised by mud. As a result, 226 families who lived in the area became homeless, and since then they have been living temporarily in hotels or properties rented by the mining company. The delay in reallocating the population reflects the limitations of the national policy in dealing with the housing issue. Despite the time lag of the tragedy, only at 
the beginning of 2018 , the urban resettlement plan was approved. The design of the parceling land, streets distribution, and blocks aims to maintain previous neighborly relations. Last year, the master plan was presented and discussed with 164 families, during 23 workshops (Fundação Renova, 2018). However, there is not an indication for the design or construction of the new housing units.

In this sense, this work aims to present a simplified model of modular housing, as a study for the district of Bento Rodrigues, in the city of Mariana, in Minas Gerais.

\section{HOUSING MASS CUSTOMIZATION}

According to Marchesi and Matt (2017), "ensuring customizable, quality housing solutions at affordable costs is becoming a pressing demand for the building industry" (p.2). In this context, Huang et al, (2006) compare "if mass production and prefabrication methods of the assembly line were the ideals of architecture in the early twentieth century, then mass customization and the development of digital technology are the recently emerged paradigms of the twenty-first century" (p.204). Despite the mass production of identical products significantly reduce costs, the results limit individual choices. On the other hand, customization allows personalized production according to consumer demand, but costs are usually high (Marchesi and Matt, 2017). "A mix of these two strategies can provide product variants and keep costs reduced" (Marchesi; Matt, 2017, p. 2). This concept has already been implemented in the computer (Dell), clothing (Lands' End), and shoe (Nike) industries, but it has not been fully adopted in housing industry (Huang et al, 2006). For the mass customization in architecture, "the aptitude of design for customization results is decisive" (Marchesi; Matt, 2017).

In this sense, the advancement of digital design tools allows data analysis that goes beyond analog capability. This contributes to an increase in the flexibility of the decisions and allows the execution of highly complex projects with more precision. It generates an infinite number of solutions for the same problem, by implementing new generative methodologies. These underutilized parametric systems can be leveraged to generate custom home solutions to both fully engage computers within an architectural design process and raise the quality of current housing practices (Wilis; Hemsath; Hardy, 2012).

Previous experiments in generating "housing design have involved shape grammar by George Stiny and discursive grammar by Jose Duarte" (Wilis; Hemsath; Hardy, 2012, p 502). Jiao and Tseng (1999) described a methodology of developing product family architecture for mass customization. Huang et al. (2006) proposed a web-based prototype that simulates the interaction between clients and the systems, an interface which aims to join an intelligent database to be used by architects, clients, and salespeople. Wills, Hemsath, and Hardy (2012) have already proposed a parametrically multi-criterionoptimized for site, roof, massing, solar orientation, and type. Bergin and Steinfeld (2012), presented the HAS, the Housing Agency System, which consists of "three main components - search Constructors, flexible parametric models and relationships which determine acceptable solutions and guide the system towards better results" (Bergin; Steinfeld, 2012).

As mentioned above, mass customization experiments for architecture production, through a parametric and algorithmic approach, have already been studied previously and present, partially or in their totality, results such as the multi-criteria design of the dwelling (implantation, volumetric variability and environmental comfort); flexible parametric models, such as tools for optimization and search for a better solutions; interfaces for client-designer interaction, which improves choice options, as well as cost optimization; life cycle assessment, and monitoring and control of construction. However, this article aims to present the first step of a simple simulation of mass customization of housing, a parametric modeling phase, as a Brazilian case study.

\section{METHODOLOGY}

This paper presents the phase of parametric modeling of flexible modular housing in grasshopper, which envisages the following phases: (1) preliminary data research, (2) conceptual architectural model, (3) parametric modeling on grasshopper, (4) BIM modeling, (5) a platform for customers interaction.

The preliminary research phase (1) consisted of a survey with the profiles of the affected families (number of people, age groups, family members), as well as the typological characteristics of the original dwellings with the purpose to analyze the ways of living in the Bento Rodrigues community. At this stage, it was possible to survey the characteristics of the affected units, which are similar to the constructive and formal pattern of Brazilian housing for families of the same income:

(a) terrain: flat plots; frontal dimensions of 15 meters to 25 meters, and depth varying between 30 meters and 70 meters, so that the units had ample yard, usually in the background; minimal or absent frontal clearance; assorted bottoms and sides;

(b) site-specific deployment: existence of balconies, on the front and side faces of housing units;

(c) use: mixed-use, housing single-family dwelling and small local commerce, usually related to the alternative economic activity of the family;

(d) height of buildings: predominance of single or two floor units;

(e) indoor compartmentalization: the rooms immediately related to the street are the garages and small commerce; bedrooms inside the lot;

(f) roof: predominance of inclined roofs; when two floors, covered terraces.

In the conceptual model phase (2), the modular system was defined to increase the volumetric variability and flexibility of the internal arrangements. "The flexible artifact is designed for choice in the design stage in terms of use and construction (from production's or the designer's viewpoint) or designed to change its lifetime (from the user's viewpoint)" (Ulrich, 2005 apud Marchesi; Matt, 2017).

Due to the intense mining activity in the region and the proximity to the production of steel in the region, the adopted constructive system is steel frame slab, leading to modular seals, unlike other Brazilian regions where the construction of concrete and masonry blocks of ceramic blocks predominates. The model allows the volumetric customization (number of blocks in linear arrangements, in $T$ and $L$, or in 1 or 2 floors), internal subdivision (houses of 1 to 4 bedrooms, with possibilities of 1 or 2 bathrooms, 
absence or existence of garage, inclusion of commercial or office room in the house).

The parametric modeling phase (3) consists of the development of the model itself, in which the design and parameters are defined.

Finally, the BIM modeling phase (4) presupposes in the design of an integrated model of the different spatial arrangements, the detailing of the constructive system, complementary installations and families of panels of sealing. It is possible to simulate environmental comfort and costs. Finally, the phase 5, the research aims the creation of a platform for customer interaction to broaden decision-making by end customers. Preliminary tests were carried out on the online platform shapediver.com, a 3D generator based on grasshopper model. However, since it does not allow visualization and simulation of surface variations, a more efficient and interactive interface would facilitate the communication with end users.
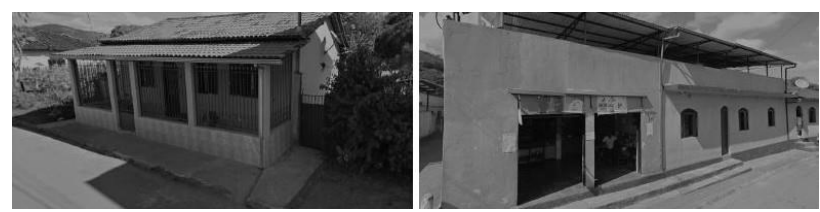

Figure 1: Residential buildings before Bento Rodrigues dam disaster. Source: google street view images. Retrieved from: www.google.com/streetview/

\section{RESULTS: THE PARAMETRIC MODELING PHASE}

The units result from the grouping of 2 modules and a maximum of 5 modules, allowing a dimensional variation from $57.60 \mathrm{~m}^{2}$ to $144.00 \mathrm{~m}^{2}$, compatible with the variability of the existing buildings in the Bento Rodrigues District prior to the environmental disaster. Each structural module adopted has $4.8 \times 6.0 \mathrm{~m}^{2}$, characterized by a system of portals with variable slope to accommodate the cover. The dimensions of this module were defined according to the closures used in steel frame structures (OSB boards), whose most common sizes are 1,20 $\mathrm{x}$ $2,40 \mathrm{~m}^{2}$ and $1,20 \times 3,00 \mathrm{~m}^{2}$ (base $\mathrm{x}$ height).

The variable parameters of the structural module are the dimensions of the column, the height of the first floor, the height of the second floor, the span between the frames, the height of the beam, the spacing of the modules and their quantities. The variable parameters of the roof are the height of the roofs, the slope in\%, amount of components and eaves.

As design possibilities, the script allows:

(a) Ground linear units: minimum of two structural modules and a maximum of 4 linear modules;

(b) Ground non-linear units: Units in L or T, originated with a minimum of 3 and a maximum of 5 modules;

(c) Two-floor units: a minimum of 3 and a maximum of 5 modules.

The grasshopper script, used as a tool for designing this project, articulates and shapes the above structures, through a set of rules, based on additions and constraints.

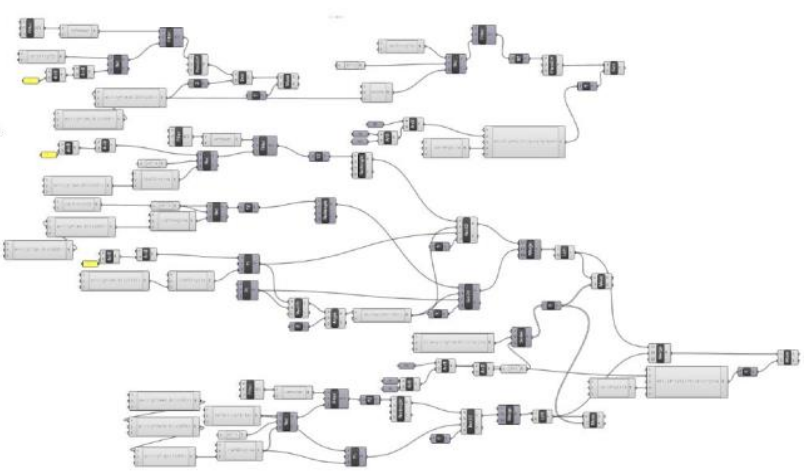

Figure 2: Script generated using Grasshopper. Source: authors.

To concentrate and rationalize the sanitary facilities, the unit has a hard core of $1.95 \times 4.00 \mathrm{~m}$ that houses a bathroom, a small laundry and a kitchen, supplied by a hydraulic wall, next to the water tank. This nucleus organizes the whole circulation of the house and allows the rearrangement of rooms and activities around it. It also houses the stairs in two-story units.

The first core position is at 3.60 meters from the boundary of the first module. It is possible to add more cores to other modules, but their activation depends on the interior of the module, to prevent them from becoming external to the unit (figures 3 and 4).

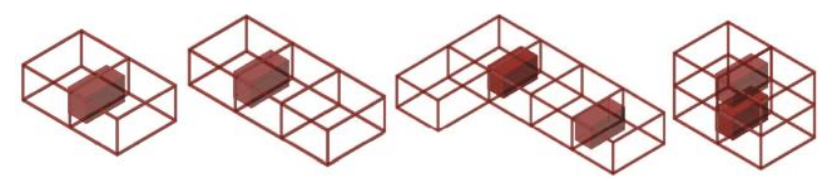

Figure 3: Options for hydro-sanitary cores in different modular groups. Source: authors.
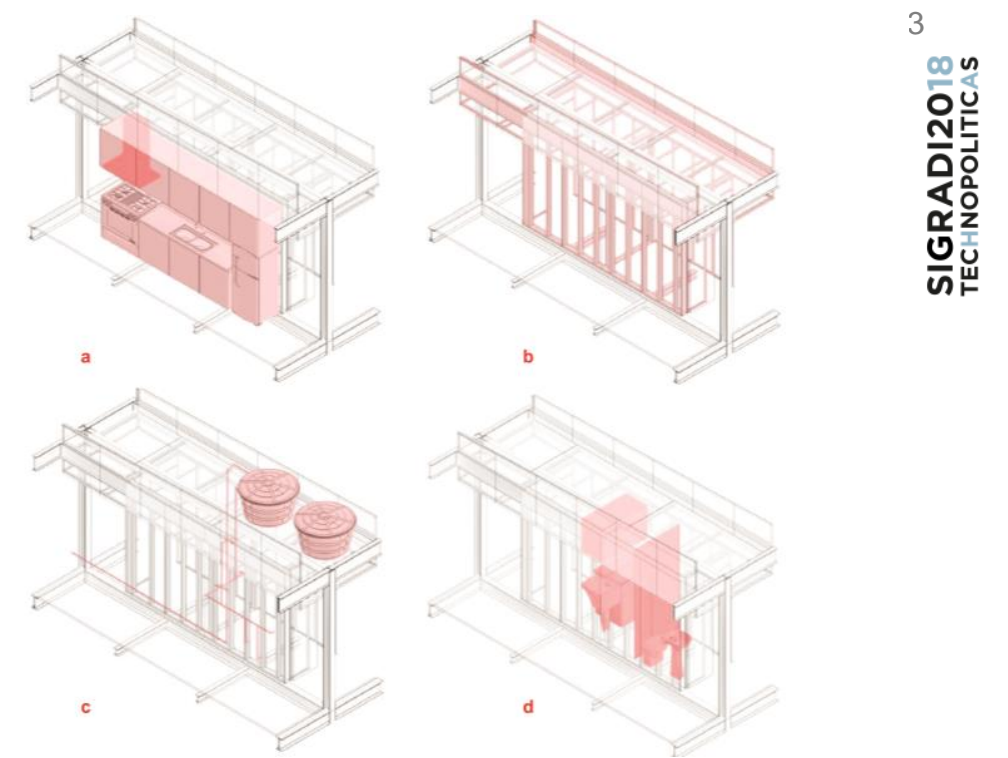

Figure 4: The rigid core concentrates sanitary facilities. (a) The kitchen, on one side of the wall; (b) the structural wall on metallic profiles of type I or U, (c) the upper water tank supplies the core that concentrates water points and sanitary sewage; (d) bathroom location and a small laundry. Source: authors.

In addition to the customization of the volume and internal compartmentation, different types of panels were designed, following the modulation of $1.20 \mathrm{~m}$, which make each unit surfaces more customizable (figure 5). 

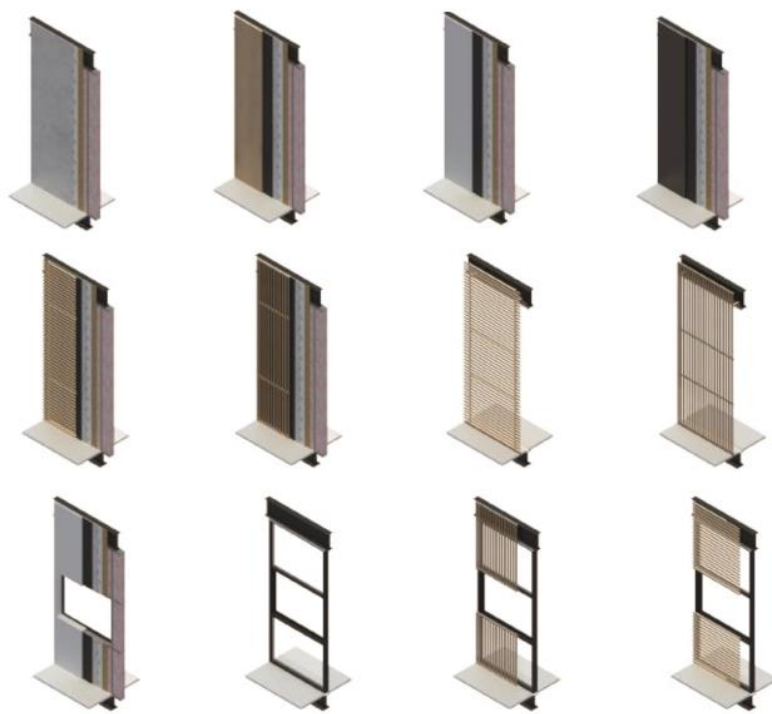

Figure 5: Options for different enclosure panels. These prefabricated panels can be made of concrete, wood, wooden or aluminum brises, guillotine windows. The panel families are in the fourth stage of the study. Source: authors.
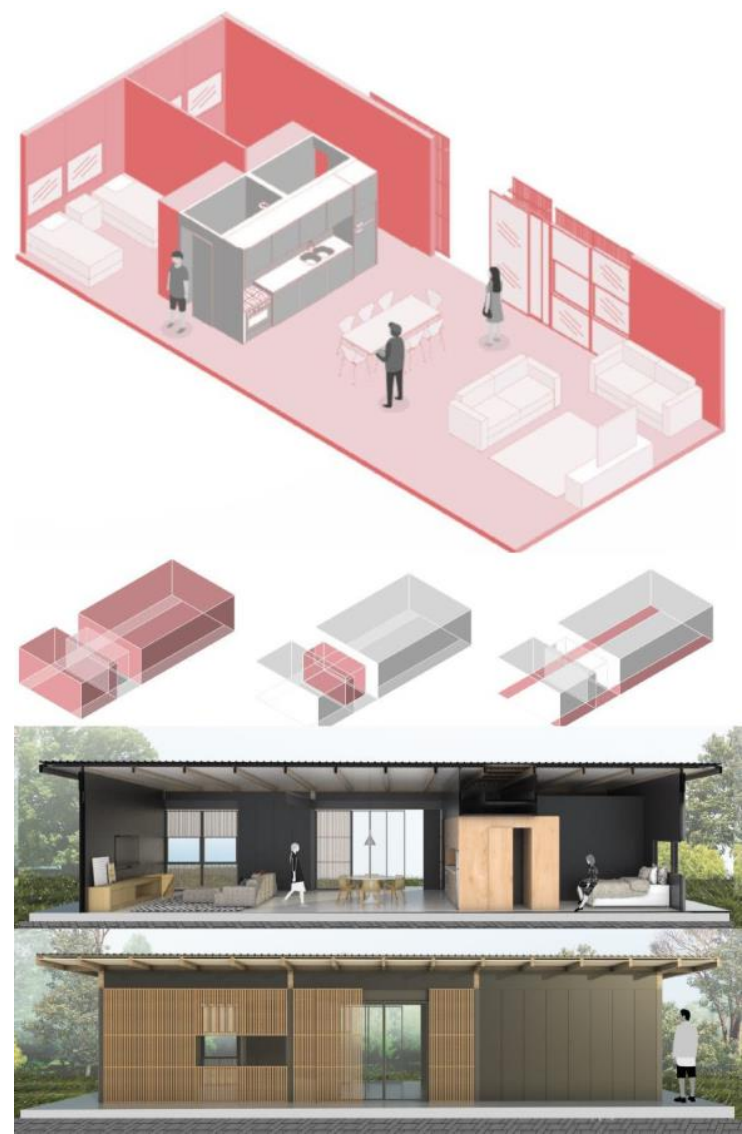

Figure 6: Some possibilities of variability. An example of a single story house, with 3 modules. Source: authors.
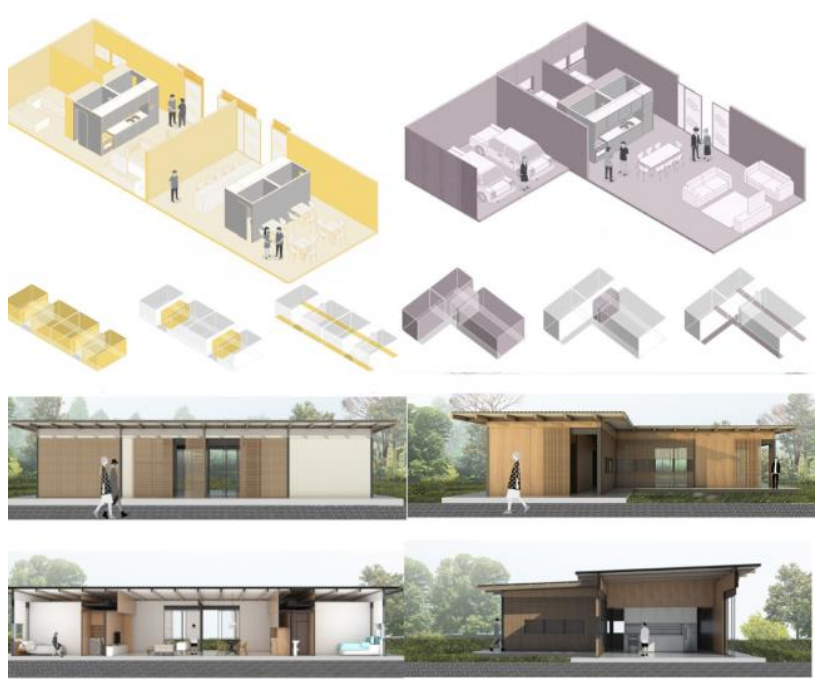

Figure 7: Some possible variations of the set. On the left, a linear house, with four modules. The front façade is destined to a local commerce, with a sanitary and kitchen. On the right, the arrangement in $L$ shows a garage for two vehicles. Source: authors.
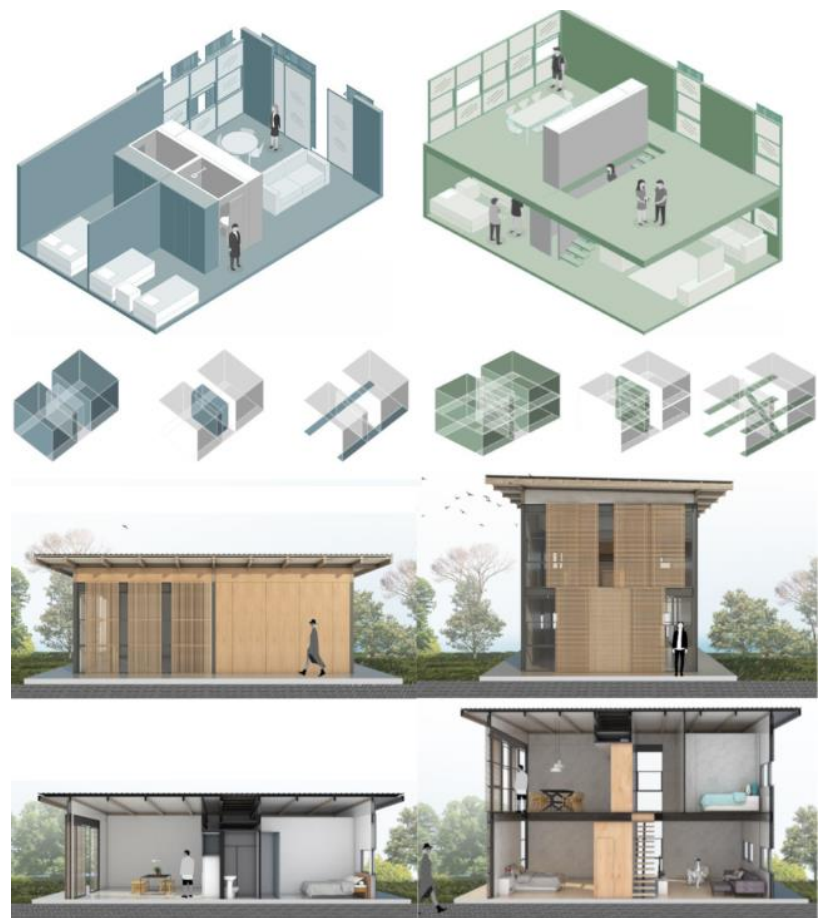

Figure 8: Some possible variations of the set. On the left, a ground house, two modules and two bedrooms. On the right, a two floors house, without an uncovered terrace, a kitchen on the upper floor and two bedrooms in the lower. Source: authors.

These are just a few pictorial options. The script allows the creation of dozens of different volumetric arrangements, each with a wide range of internal subdivisions, which change the possibilities of use according to the users' choices (figures 6, 7 and 8). There are other options with front and side balconies, internal courtyards and different indoor subdivisions. The modularity of the facade panels enhances the variability of the complex as well as the surface treatment according to the specific conditions of the terrain (solar orientation, prevailing winds, among others). 
The prefabricated construction system in metallic structure and steel frame slab, which besides using the abundant raw material in the region, also rationalize the construction process (figures 9 and 10).

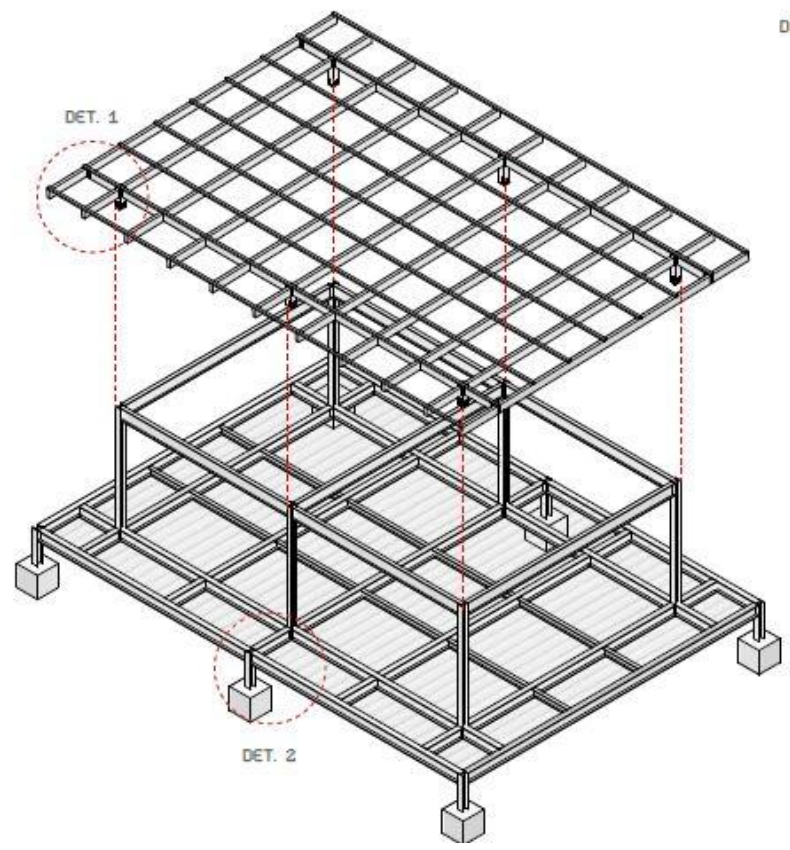

Figure 9: The structural system for flat terrains. Source: authors.

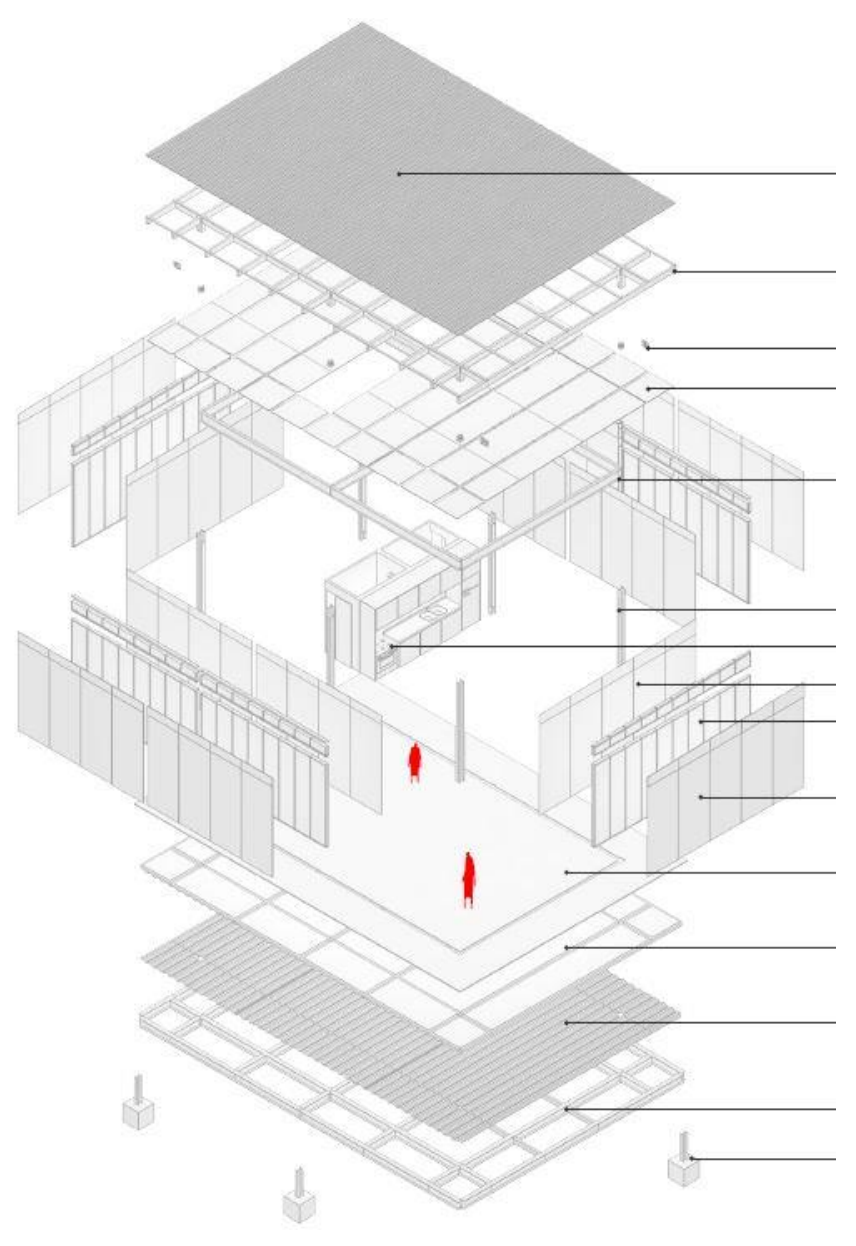

Figure 10: Diagram of the assembly components of a singlestory house. Source: authors.

\section{CONCLUSION}

The design is a simple mass customization experiment for social housing on grasshopper. Despite the great possibility of parametric choices, the script still has limitations on detailing the building. The next stages of development are optimization of environmental comfort (insolation, ventilation, thermal inertia, among others on grasshopper plugins (Octopus, honeybee, among others) or through BIM (phase 04). In the fourth phase, the interoperability between Dynamo-Revit pair will be tested. The BIM phase aims to facilitate the detailing, the definition of costs and the control of the construction.

Recently the decree of a federal law, on May 17, 2018, instituted the national strategy of dissemination BIM in Brazil. The stimulus to the use of building information modeling in the public sector, integrated to generative processes of design for the mass customization, can reduce the main criticisms to the Brazilian model of design and construction of social housing in the next years.

Finally, the research intends to implement, in phase 05, a more effective communication platform between the designer and the end-users, which allows the visualization and greater range of choices. Currently, the simplified model is available on the online platform shapediver.com. However, despite the interactivity in the parameter change, it does not adequately present all the possibilities of internal compartmentalization and use, nor of surface customization. A more user-friendly graphical interface should be developed to facilitate communication and freedom of choices for end costumers.

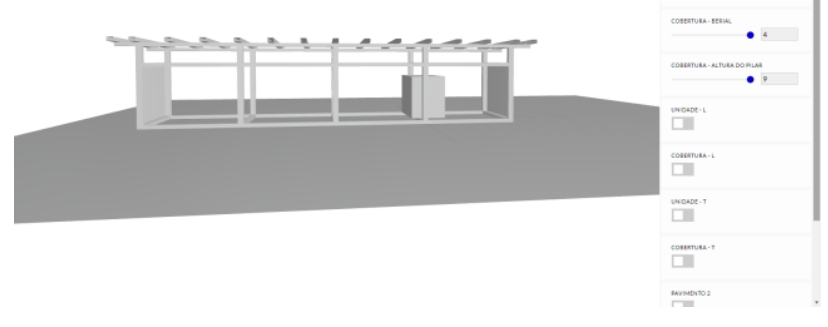

Figure 11: Available at shapediver.com/m/tcc-jorge-lira-1.

\section{ACKNOWLEDGMENTS}

We thank to PPG.au (The Graduate Program in Architecture and Urbanism) and the Department of Architecture and Urbanism at Federal University of Viçosa (DAU/UFV), for supporting this work.

\section{REFERENCES}

Bergin M.; Steinfeld, K. (2012). Housing Agency System (HAS): multi-criteria satisficing and mass customization of homes. CSA Fall Conference, Philadelphia, 93-97.

Correia, R.; Duarte, J.; Leitão, A. (2012). GRAMATICA: A general $3 \mathrm{D}$ shape grammar interpreter targeting the mass customization of housing. ECAADE, 30, Praga. Shape Studies. Praga: Ctu, v. 1,489 - 496.

Gramazio, F.; Kohler, M. (2014). The Robotic Touch: How robots change Architecture. Zurich: Park Books.

Fundação Renova (2018). Projeto urbanístico de Bento Rodrigues é aprovado por 99,4\% das famílias em assembleia 
geral: O novo distrito deverá preservar, ao máximo, as características originais de Bento Rodrigues. Retrieved from www.fundacaorenova.org/noticias/

Huang, J. C.H; Krawczyk, R. J. (2006): i_Prefab Home. Customizing Prefabricated Houses by internet-Aided Design. Proceedings.... 24 $4^{\text {th }}$ eCAADe Conference.

Leach, N. (2014). Parametric Explained. Next Generation Building. Baltzer Science Publishers. v.1, n.1, p.1- 9.

Mark, E., Gross, M. Goldshmidt, G. (2008). A perspective on Computer-Aided Design After Four Decades. In: Proceedings...ECAADe 26, Antwerpen: CAAD Curriculum, p. 169-176.

Marchesi, M.; Matt, D. (2017) Design for Mass Customization: Rethinking Prefabricated Housing Using Axiomatic Design. Journal of Architectural Engineering (ACSE), pp. 1-20.

Mikkola, J. (2007). Management of Product Architecture Modularity for Mass Customization: Modeling and Theoretical Considerations. IEEE Transactions on Engineering Management, vol. 54, n. 01, February.

Mitchell, W. J. (1990), The Logic of Architecture: Design, Computation, and Cognition. Cambridge: MIT Press.

Oxman, R. (2017) Thinking difference: Theories and models of parametric design thinking. Design Studies 52. pp. 4-39. Available from: https://www.researchgate.net/publication/ 318064292_Thinking_difference_Theories_and_models_of_p arametric_design_thinking. [accessed Feb 19 2018].

Ulrich, K. T. (2005). Design: Creation of artifacts in society, Univ. of Pennsylvania, Philadelphia.

Vincent, C., Nardelli, E. and Nardin, L. Parametrics in Mass Customization. Proceedings.... SiGraDi 2010, Bogotá: Blucher, pp. 236-239.

Willis, B. R.; Hemsath, Timothy L.; Hardy, Steve (2012). A parametric Multi-Criterion Housing Typology. Proceedings.... $32^{\text {nd }}$ ACADIA Conference. 